\title{
Towards Optimizing a Personal Cooling Garment for Hot and Humid Deep Mining Conditions
}

\author{
Chady Al Sayed, Ludwig Vinches, Stéphane Hallé \\ Department of Mechanical Engineering, École de Technologie Supérieure, Montréal, Canada \\ Email:chady_sayed@hotmail.com
}

Received 2 February 2016; accepted 8 March 2016; published 11 March 2016

Copyright (C) 2016 by authors and Scientific Research Publishing Inc.

This work is licensed under the Creative Commons Attribution International License (CC BY). http://creativecommons.org/licenses/by/4.0/

c) (i) Open Access

\begin{abstract}
Workers exposed to hot and humid conditions suffer from heat stress that affects their concentration and can potentially lead to an increase in workplace accidents. To minimize heat stress, protective equipment may be worn, such as personal cooling garments. This paper presents and discusses the performances, advantages and disadvantages of existing personal cooling garments, namely air-cooled, liquid-cooled, phase change, hybrid, gas expansion and vacuum desiccant cooling garments, and a thermoelectric cooling technology. The main objective is to identify the cooling technique that would be most suitable for deep mining workers. It appears that no cooling technology currently on the market is perfectly compatible with this type of mining environment. However, combining two or more cooling technologies into a single hybrid system could be the solution to an optimized cooling garment for deep mines.
\end{abstract}

\section{Keywords}

Personal Cooling Garment, Heat Stress, Thermal Efficiency, Deep Mines

\section{Introduction}

The mining industry has been an important part of the world economy for over a century. Many metals and minerals (nickel, silver, uranium, gold, copper, etc.) used in most human products like batteries, vehicle tires and computers are extracted from ore located below the surface. With the increasing of the global demands in products and the innovation of technology, mining goes even deeper to meet the demands of materials [1]. In mines, especially deep mines, miners face a hard work environment caused by high humidity levels (that can easily reach 80\%) and high ambient temperatures. Among other things, these harsh conditions stem from air self- 
compression (an approximately $9^{\circ} \mathrm{C}$ increase for every $1 \mathrm{~km}$ of depth), the heat produced by vehicles and mining equipment and the temperature of the rocks that can reach up to $50^{\circ} \mathrm{C}$ [2] [3].

The human body continually seeks to maintain its internal temperature at $37^{\circ} \mathrm{C}$. In order to maintain its temperature, the body heat production mechanisms (mainly the metabolic heat) must be equal to the heat loss mechanisms. Figure 1 presents schematically the three heat loss mechanisms from the body to the environment (heat loss through respiration is negligible). The efficiency of these heat extraction modes depends strongly on the dry bulb and wet bulb temperature as well as the mean radiant temperature. In hot environments, sweating is the body's prime way of removing excess heat. However, because the relative humidity $(\mathrm{RH})$ in deep mines is usually very high, the efficiency of this mechanism is limited. The ventilation and the cooling of the air are essential in mines to remove the heat and provide an acceptable air quality. However, it appears that their efficiencies are limited as the mining gets deeper. The miners exposed to heat stress, might encounter fatigue, headache, cramps, dizziness, vomiting, unconsciousness and lacks of concentration [4]. All those symptoms could increase the risk of work accidents and cause a significant decrease in productivity. Therefore, it becomes necessary to assist the body's thermoregulation system with an artificial cooling technique.

The purpose of this paper is both to present and discuss the performances of existing cooling garments, and to identify cooling techniques adapted to the mining industry that could be used to optimize the performance of personal cooling garments.

\section{Personal Cooling Garments and Cooling Technologies}

Personal cooling garments currently play a very important role in reducing heat stress for athletes, firefighters and workers subject to extreme climate conditions [5]. These cooling garments can be classified into two categories: passive and active garments.

Passive garments do not involve any mechanical or electrical equipment in order to function and can be divided into two known types: the phase-change garment, or PCG, and the cooling garment, based on vacuum desiccant cooling. The well-known types of active garments are: air-cooled garments or ACG, liquid-cooled garments named LCG, cooling garments based on gas expansion and hybrid cooling garments. In this paper, another type of active cooling technology will be discussed with its advantages and disadvantages: thermoelectric cooling.

\subsection{Air-Cooled Garment (ACG)}

Air-cooled garments contain two layers of which the outer layer is impermeable to the surrounding air, and the second is air-permeable and in direct contact with the skin. Air is blown between the two layers and exits the garment through the inner layer towards the skin [5] [6]. The ACG's primary mode of cooling is by evaporating the body's sweat. However, the efficiency of air-cooled garments in environments with high humidity levels is severely limited [7].

In 1987, Muza et al. found that for a low metabolic rate ( $175 \mathrm{~W})$, an ACG that supplies $4.72 \mathrm{l} / \mathrm{s}$ of air flow at $25^{\circ} \mathrm{C}$ is more effective in reducing thermal stress and extending endurance time than a garment that supplies 6.6

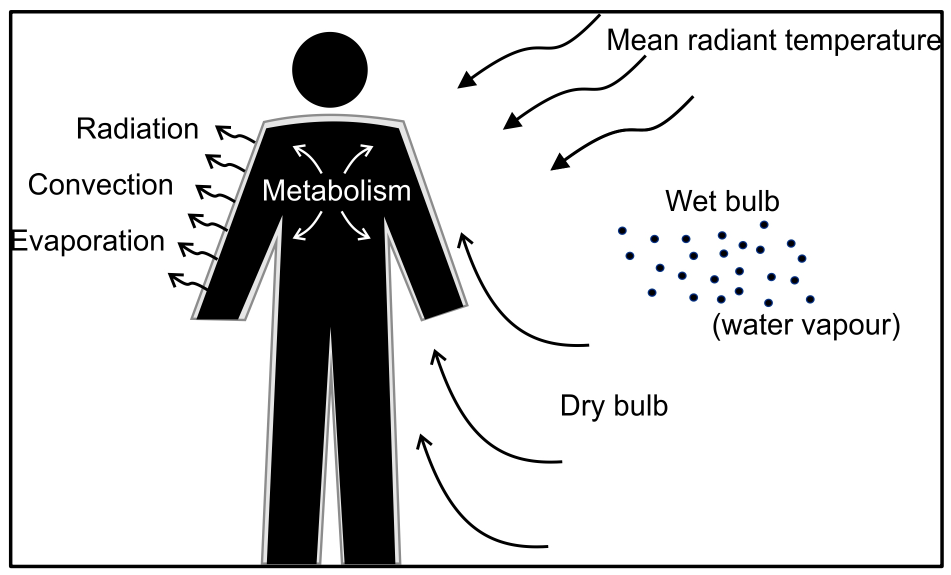

Figure 1. Representation of the body's heat loss mechanisms. 
l/s. At a higher metabolic rate $(315 \mathrm{~W})$, the garment at $6.6 \mathrm{l} / \mathrm{s}$ of air flow extended the endurance time further, but was not as effective in reducing thermal strain as the $4.72 \mathrm{l} / \mathrm{s}$ garment [8].

In 1991, Vallerand et al. found that in a dry bulb of $37^{\circ} \mathrm{C}, 50 \% \mathrm{RH}$, and metabolic rate of about $240 \mathrm{~W}$, the ACG can increase productivity of subjects up to 58\% [9]. A few years later, McLellan et al. found that in a hot and dry environment $\left(40^{\circ} \mathrm{C}\right.$ and $\left.30 \% \mathrm{RH}\right)$, the air-cooled garment increases the tolerance time by $80 \%$ in light work, and $150 \%$ in heavy work [10]. Chinevere et al. noted a $20.8 \%$ improvement in the productivity of the subjects in a $35^{\circ} \mathrm{C}$ and $75 \% \mathrm{RH}$ environment, after the use of an air-cooled garment [11].

According to Pandolf et al., to maximize the efficiency of this garment, the air flow must be designed so the air finishes its passage over the skin before being completely saturated with moister [12]. In 2009, Barwood et al. reported that the air-cooled vest used in their tests provide more cooling at rest (73 W of heat loss) than during exercise (28 W). This was probably due to improved air circulation under the vest when the subjects were seated [13].

In 2015, Glitz et al. studied an air-cooled garment designed as a pair of overalls with long sleeves and legs. Dehumidified air at 5\% relative humidity was generated by a stationary compressor and injected into the garment at a ventilation rate of $10 \mathrm{l} / \mathrm{s}$. In a $25^{\circ} \mathrm{C}$ and $50 \% \mathrm{RH}$ environment, the evaporative heat loss calculated was $208 \mathrm{~W}$ [14]. In the same year, Zhao et al. studied an air-cooled garment with long sleeves in a climate of $32^{\circ} \mathrm{C}$ and 50\% RH with eight female subjects. The garment's performance results indicate a low efficiency in reducing the body's thermal physiological responses, but they stated that the garment could be used, after exercising in mild heat, to improve thermal comfort and reduce heat stress [15].

\subsection{Liquid-Cooled Garment (LCG)}

Liquid-cooled garments (LCGs) use a cooled fluid (generally water) that circulates, within tubes embedded in the garment, using a micro-pump powered by a battery [16]. These tubes are usually made of polyvinyl chloride (PVC) [17]-[20]. Many studies conducted on subjects wearing LCGs show that these garments can significantly improve performance (work duration) and decrease thermal strain. Work is improved by $54 \%$ according to Kim et al. [21] [22], 58\% according to Vallerand et al. [9] and even reaches $80 \%$ in a study by McLellan et al. [10].

Speckman et al. found that the water circulating in a liquid-cooled garment should be at a minimum temperature of $10^{\circ} \mathrm{C}$ depending on the wearer's comfort, and that increasing the amount of body surface in contact with this garment increases its cooling efficiency [23]. In 2014, Bartkowiak et al. concluded that significant improvement of the thermal sensations of a worker in a hot environment $\left(35^{\circ} \mathrm{C}\right.$ and $\left.30 \% \mathrm{RH}\right)$ can be achieved with a coolant temperature equal to $19^{\circ} \mathrm{C}$ and a flow rate of $0.9 \mathrm{l} / \mathrm{min}$ [24].

Studies conducted on firefighters concluded that using a liquid-cooled garment under their personal protective equipment improves performance time and helps the body recover within a shorter period of rest [21] [22]. However, with LCGs, there is a risk of skin burn caused by the stream formation that may appear if the water was circulated in the space between the skin and the personal protective equipment [25].

To increase the effectiveness of an LCG, coolant temperature and mass flow must be monitored and controlled [5]. Cadarette et al. found that when a LCG is power-controlled in a pattern of 2 minutes on and 2 minutes off, it will have the same cooling efficiency as an LCG in continuous operation, since even if the coolant does not circulate in the tubes, it will still passively absorb heat [26]. Moreover, Vernieuw et al. conclude that to maximize the cooling period of a garment, it should be controlled by the wearer's skin temperature [27].

\subsection{Cooling Garment Based on Gas Expansion}

This type of cooling garment does not require power to function and is based on the endothermic vaporization of liquefied carbon dioxide $\left(\mathrm{CO}_{2}\right)$ [28]. High pressure $\mathrm{CO}_{2}$ is dispensed through an expansion valve in which the gas pressure drops to the ambient value. In this thermodynamic evolution, liquid $\mathrm{CO}_{2}$ flashes to vapor and absorbs energy equal to the gas' heat of vaporization. As described by Zhang et al., "the newly vaporized cool and dry $\mathrm{CO}_{2}$ is vented over a thin textile layer ( $100 \%$ cotton blended fabric) in direct contact with the skin, providing further cooling to the extent that it enhances ambient sweat evaporation" [29].

The gas used in this garment is carbon dioxide. Since high levels of $\mathrm{CO}_{2}$ can be toxic, its use in closed spaces requires that the concentration of $\mathrm{CO}_{2}$ be monitored to prevent intoxication. Zhang et al. measured a maximum concentration of $4000 \mathrm{ppm}$ (10 times the normal level found outdoors) in their $29.5 \mathrm{~m}^{3}$ lab area while testing one garment. A great advantage of the garment is that it is light $(1.3 \mathrm{~kg})$, but a disadvantage is that its cooling period is limited to 25 minutes for a single bottle of $\mathrm{CO}_{2}$ [29]. 


\subsection{Phase Change Garment (PCG)}

The phase-change garment uses materials that have the ability to absorb and store thermal energy in latent heat form at a temperature range suitable for personal cooling purposes [5]. In general, a PCG covers the torso and contains pockets surrounding the chest cavity that hold the phase changing material packs [30] [31].

The conclusions of many studies conducted on this type of cooling garment vary greatly as to its performance and cooling effectiveness. Such conflicting results may be explained by variations in the weight of the phasechange material, its repartition and the climate conditions where the studies were conducted.

In 1991, Bain evaluated the effectiveness of a portable ice-pack cooling vest in prolonging the work tolerance time at a dry bulb temperature of $33^{\circ} \mathrm{C}, 33 \% \mathrm{RH}$ and approximately $700 \mathrm{~W}$ metabolic rate. He concluded that the cooling vest was ineffective in prolonging work tolerance time and did not affect the response of rectal temperature or sweat loss [32]. A similar conclusion was reached by Kauffman et al., in a hot and humid environment $\left(37^{\circ} \mathrm{C}, 75 \% \mathrm{RH}\right)$ and 572 to $636 \mathrm{~W}$ metabolic rate. They found that when used with an impermeable protection cloth in extremely hot and humid environments, the PCG offers no physiological advantage [33].

Bennett et al. found that two cooling vests, one with four packs of a phase-changing material and the other with 6 packs, had the same effect on reducing heat strain for the same subjects during a 60-minute work activity $\left(34.4^{\circ} \mathrm{C}\right.$ and $\left.55 \% \mathrm{RH}\right)$. The vests raised the performances of the subjects by approximately $29 \%$. After a $60-$ minute work period, the 6-pack vest seems to have had a more beneficial effect on reducing the thermal and cardiovascular strain experienced by the subjects [31].

In 2011, Kenny et al. evaluated the effectiveness of a personal ice cooling vest, worn under a nuclear biological chemical suit in a $35^{\circ} \mathrm{C}$ and $65 \% \mathrm{RH}$ environment. They concluded that the ice-cooled vest is an effective way to reduce the heat stress of individuals performing nonstop work over long periods (up to 2 hours) in uncompensable heat stress conditions [34].

In one study, House et al. assessed the effectiveness of four phase-change garments containing materials that melted at $0^{\circ} \mathrm{C}, 10^{\circ} \mathrm{C}, 20^{\circ} \mathrm{C}$ and $30^{\circ} \mathrm{C}$ in a $40^{\circ} \mathrm{C}$ and $46 \%$ RH environment and that were worn beneath firefighter protective clothing. They ascertained that a cooling vest containing the phase-changing material that melted at $10^{\circ} \mathrm{C}$ has the best cooling efficiency when combining work and rest periods. They also stated that a cooling vest containing ice packs (melting at $0^{\circ} \mathrm{C}$ ) could be used only if the thermal resistance between the ice packs and the skin was higher [35].

\subsection{Cooling Garment Based on Vacuum Desiccant Cooling}

A prototype of a cooling garment based on vacuum desiccant cooling was tested in $40^{\circ} \mathrm{C}$ and $50 \% \mathrm{RH}$ climate conditions by Yang et al. [36]. The cooling garment pad contained: a cooling core containing water, an absorption core, a honeycomb-type spacer, and an outer bag made of plastic. The prototype weighed approximately 3.4 $\mathrm{kg}$ and covered $0.4 \mathrm{~m}^{2}$ of body surface. Yang et al. found that this prototype has a maximum cooling capacity of $373 \mathrm{~W} / \mathrm{m}^{2}$ and concluded, that this prototype is more effective than a commercially available ice-cooling vest at decreasing the core body temperature and heat stress while the wearer is working in a hot environment [36].

\subsection{Thermoelectric Cooling}

Thermoelectric devices used in thermoelectric cooling are based on the Peltier effect to convert electrical energy into a temperature gradient [37] [38]. To the best of our knowledge, there is no publication in which a cooling garment using Peltier effect was tested. A single stage thermoelectric module uses type- $\mathrm{N}$ and type-P semiconductors connected properly [37] [39]. When a direct current passes through the junctions of athermoelectric module, the difference in temperature between the opposite sides can reach $70^{\circ} \mathrm{C}$, and may transfer up to $125 \mathrm{~W}$ of heat [40]. A thermoelectric module offers many advantages, namely: its small size, high reliability, no vibrating parts and direct energy conversion. On the other hand, their main weakness is the poor coefficient of performance (COP), particularly in large capacity and wide temperature range applications [41].

\subsection{Hybrid Cooling Garments}

Hybrid cooling garments combine two or more cooling techniques in one functional system. The most wellknown type is the air-liquid cooling garment used by the National Aeronautics and Space Administration (NASA) for extravehicular activities in space. It contains elastic Spandex, vinyl tubes through which a coolant 
circulates and an airflow duct, which is stitched over the garment that mostly cools the head [42].

In another study, Kim et al. examined the efficiency of a liquid-cooled garment worn under a fully equipped prototype of a firefighter ensemble incorporating a self-contained breathing apparatus (SCBA). In the study, the exhaust gases were routed from the SCBA into the fully equipped prototype firefighter ensemble and Kim et al. concluded that by combining the LCG and air ventilation, the total performance time increases by approximately $82 \%$ [21].

In 2014, Chan et al. studied the impact of wearing a cooling vest equipped with two fans and three gel packs, on physiological responses, subjective perceptions of thermal comfort and perceived exertion. The system was tested in four different industries in Hong Kong during summer days: construction, horticulture and outdoor cleaning, airport apron, and catering and kitchen. The cooling effect of this hybrid vest was provided by two fans at the back, three gel packs located on the chest and on the back side of the vest. The total weight of the cooling equipment with vest, fans and gel packs was about $1 \mathrm{~kg}$. This hybrid vest enabled participants to support about 2 hours of heat exposure without marked heat strain and did not restrict the movement of individuals nor adversely affect job performance [43].

Recently, Lu et al. studied the performance of a new hybrid cooling uniform incorporating both ventilation fans and phase-change materials in a $34^{\circ} \mathrm{C}$ dry bulb environment with $75 \% \mathrm{RH}$ (hot and humid) and $28 \% \mathrm{RH}$ (hot and dry) respectively. The uniform set consisted of a long sleeve jacket and a pair of long pants with two ventilation units and 24 packs of phase changing material (PCM). Its total weight was of $3.6 \mathrm{~kg}$. They concluded that this hybrid cooling uniform provides a continuous cooling effect during the three-hour test and the average cooling rate for the whole body is around $111 \mathrm{~W}$ and $315 \mathrm{~W}$ in "hot and humid" and in "hot and dry" conditions respectively [44].

\section{Advantages and Disadvantages of the Cooling Garments and Technologies in a Deep Mining Environment}

Miners working in deep and ultra-deep mines are exposed to severe work conditions. First, there are conditions of extreme heat-stress. Air temperature can reach $40^{\circ} \mathrm{C}$ with a relative humidity of $80 \%$ [2] [3]. Then, there is the basic safety clothing each worker must wear. Regulations pertaining to occupational health and safety in mines oblige every person in an underground mine (except in a lunchroom, a cab or an office) to wear a body harness or safety belt along with a safety hat, sight-adjusted protective glasses or a face shield and safety shoes all of which can be a big load that the worker must carry [45]. And finally, the work itself is physically demanding. Some jobs in the mining industry, such as manual bolting and general services, require energy expenditures that can exceed $500 \mathrm{~W}$ per worker [46].

The air-cooled garment is considered to be a light-weight garment (0.6 kg [15], $1 \mathrm{~kg}$ [47], $1.2 \mathrm{~kg}$ [7], $1.3 \mathrm{~kg}$ [13] and $3 \mathrm{~kg}$ [14]), which is important in the case of miners who already wear a heavy load of protective gear (boots, overalls, body harness, face shield, safety hat, batteries, etc. [45]). The ACG keeps clothing drier and relies on the body's own mechanism (sweat) to dissipate heat thusly eliminating the risk of overcooling that could occur with other types of garments [12]. At high levels of RH, the efficiency of the air-cooled garment decreases, because the ambient air is saturated [11]. It was concluded also, that cooling the air before it passes over the skin can raise the performance of this type of garment, especially in hot environments [9] [48]. The autonomy of ACGs relies on that of the electric batteries supplying the fans. Because of the low energy consumption of the fans, some of these garments can operate 12 hours nonstop. The space between the body and the inner layer of the garment affects heat transfer. It is recommended that a gap be maintained between the vest and the skin to maximize the evaporation of sweat [7].

The liquid-cooled garments are heavier than those using an air-cooling technique [12] [47]. Also, if the tubes imbedded in the vest are compressed, interruption of liquid flow can occur [12]. It is recommended that the design of the liquid-cooled garments include a cooling control to enable the adjustment of the coolant temperature and flow circulation on the basis of undergarment temperature changes (skin temperature) [24] [26] [27]. If the metabolic activity decreases, the miner may experience unwanted body heat loss and thermal discomfort [12]. In a humid environment, if the water circulates in the space between the skin and the personal protective equipment, steam may appear and cause skin burns [25]. When the ambient air temperature is higher than the liquid coolant as is the case in deep mines, the coolant can gain heat from the environment resulting in a heat transfer that will reduce its cooling efficiency. 
The cooling garments based on gas expansion weigh less than $1.4 \mathrm{~kg}$ [29], but the amount of time they operate is considered very low (just 25 minutes for each $0.45 \mathrm{~kg}$ pressurized bottle) compared to other cooling garments. However, Zhang et al. found that this type of garment has a sensible cooling power of $136 \mathrm{~W}$ that can easily be used to lower the thermal strain of a miner. Other than the short operating span, the major problem that appears is that the $\mathrm{CO}_{2}$ exhaust is released into mines, which are a closed environment. If several miners use this cooling garment in the same place, hazardous $\mathrm{CO}_{2}$ concentrations may be reached [29] [45].

The most widely known hybrid garments operate using a combination of two cooling techniques: liquid-air cooling [21] [42] or phase changing material-air cooling [43] [44] [49]. Hybrid garments appear to be more efficient than the traditional garments that operate using a single technology [21] [42] [44]. The effective cooling duration of a hybrid garment will correspond to the lowest cooling duration of its incorporated techniques. For the phase-changing material and air cooling garment, the phase-changing material will determine the effective cooling duration. Once the phase-changing material melts, the hybrid garment will still provide some cooling by its fans, but with a much lower efficiency. It also appears that these garments are more cumbersome than the traditional single technology garments.

The phase-change garment does not require an external source of energy to operate making this system very simple. However, its effectiveness appears to be the lowest among the types of cooling garments [25] [29] [32] [33] [36] and a PCG requires direct contact with the skin for higher efficiency. These garments have an operating time of approximately 2 hours for a $4 \mathrm{~kg}$ garment [34]. The cooling time can be extended to several hours, but at the cost of significantly increasing the garment's weight, which will raise the energy expenditure of the miner.

Yang et al. found that garments based on vacuum desiccant cooling were more effective at decreasing the core body temperature and heat stress than a $4.1 \mathrm{~kg}$ commercial PCG [36]. However, to the best of our knowledge, only one paper was published on this garment and the system was tested with only one subject.

A thermoelectric cooling module can generate a low temperature on its cold side and has a high cooling capacity in proportion to its small size. The cooling and temperature can easily be modified by adjusting the power supply connected to the module and therefore can be used to control the level of cooling provided by the garment [37]. It is a silent component with no moving parts and can be incorporated into an existing cooling garment to increase the cooling effect. The disadvantages of this technique are: the relatively high electric energy consumption requiring a good-sized battery and the COP, particularly when the efficiency of the heat sink of the hot side is low [40] [41].

\section{Discussion}

Many factors must be taken into consideration when optimizing a cooling garment for miners. The first relate to the work environment, namely high temperature and humidity levels. The second factor pertains to the compatibility of the garment with the miner's safety equipment and considerations regarding the current laws and regulations on for example, the use of pressurized bottles, the type of batteries allowed and the maximum concentration of carbon dioxide allowed in mines. The third concern the autonomy of the cooling system, the weight of the garment, and its efficiency.

In a humid environment such as that found in deep underground mines, the high humidity level will affect the cooling efficiency of an air-cooled garment that works by evaporating sweat. In liquid-cooled and phase-change garments, this high RH will increase the risk that condensation will form on the inner surface of the garments. Moreover, the high dry bulb temperature will heat the liquid in an LCG and rapidly melt the cooling pads in a phase-change garment or a vacuum desiccant cooling garment. In an ACG, the circulating air will either be only slightly cooler or much warmer than the skin and the cooling effect will be minimal or inexistent.

Liquid-cooled garments tend to be bulky, which can interfere with the safety equipment and mobility of a miner. Garments based on PCM and gas expansion, appear to have low autonomies, which would generate downtime in an industry faced with strict demands on productivity. Moreover, the carbon dioxide garment might not be permitted by mining regulations, or in places where many miners work in the same area and the concentration of $\mathrm{CO}_{2}$ could rise to hazardous levels.

Currently, no cooling technology appears to be perfectly compatible with the reality of deep underground mines. The solution may lie in the combination of two (or more) cooling technologies with the design of a hybrid garment that takes into consideration the constraints associated with the miner's activities and the extreme 
thermal environment found in deep mines.

Among the different combinations, some deserve to be studied more carefully. For example, coupling thermoelectric modules with phase-changing materials may be a good option to increase the autonomy of the cooling pad. An LCG combined with a dry compress air system might also be able to increase the sensible and latent heat loss from the body.

\section{Conclusion}

This paper presented the advantages and inconveniences of personal cooling garments with regard to a deep mining environment. It is possible to conclude that each cooling technology presents some advantages and drawbacks. Currently, no cooling technology seems to meet the level of performance required for deep underground environments. Combining two or more technologies in one hybrid garment could be the solution to a better cooling garment adapted for the mining industry. This cooling garment should be light, compatible with the work of miners, present no risk to health and safety and significantly reduce heat stress. Therefore, further investigations and studies on different combinations of cooling technologies must be conducted to reach an optimal cooling garment that is adapted for miners in deep mines.

\section{Acknowledgements}

This research was supported by the Fond Québécois de Recherche Nature et Technologie (FQRNT).

\section{Conflict of Interest}

The authors declare that they have no conflict of interest with the technologies and garments presented herein.

\section{References}

[1] Marshall, B. (2014) The Mining Association of Canada (MAC): Facts and Figures of the Canadian Mining Industry. W.C.E. Associates, Editor.

[2] Hartman, H.L., et al. (2012) Mine Ventilation and Air Conditioning. John Wiley \& Sons, Hoboken.

[3] Piekarski, C. (1995) Climatic Stress in Coalmining in Germany: Occupational Health Aspects. Ergonomics, 38, 23-35. http://dx.doi.org/10.1080/00140139508925082

[4] Michael Donoghue, A. (2004) Heat Illness in the U.S. Mining Industry. American Journal of Industrial Medicine, 45, 351-356. http://dx.doi.org/10.1002/ajim.10345

[5] Mokhtari Yazdi, M. and Sheikhzadeh, M. (2014) Personal Cooling Garments: A Review. The Journal of the Textile Institute, 105, 1231-1250. http://dx.doi.org/10.1080/00405000.2014.895088

[6] Weber, S. (1999) Air Cooling Garment for Medical Personnel. Google Patents.

[7] Hadid, A., et al. (2008) Effect of a Personal Ambient Ventilation System on Physiological Strain during Heat Stress Wearing a Ballistic Vest. European Journal of Applied Physiology, 104, 311-319. http://dx.doi.org/10.1007/s00421-008-0716-8

[8] Muza, S.R., Pimental, N.A. and Cosimini, H.M. (1987) Effectiveness of an Air Cooled Vest Using Selected Air Temperature, Humidity and Air Flow Rate. Combinations, DTIC Document.

[9] Vallerand, A., et al. (1991) Heat Balance of Subjects Wearing Protective Clothing with a Liquid- or Air-Cooled Vest. Aviation, Space, and Environmental Medicine, 62, 383-391.

[10] McLellan, T., Frim, J. and Bell, D. (1999) Efficacy of Air and Liquid Cooling during Light and Heavy Exercise While Wearing NBC Clothing. Aviation, Space, and Environmental Medicine, 70, 802-811.

[11] Chinevere, T.D., Cadarette, B.S., Goodman, D.A., Ely, B.R., Cheuvront, S.N. and Sawka, M.N. (2008) Efficacy of Body Ventilation System for Reducing Strain in Warm and Hot Climates. European Journal of Applied Physiology, 103, 307-314. http://dx.doi.org/10.1007/s00421-008-0707-9

[12] Pandolf, K., et al. (1995) Tri-Service Perspectives on Microclimate Cooling of Protective Clothing in the Heat. Natick, MA. US Army Research Institute of Environmental Medicine, Technical Report No. T95, 10.

[13] Barwood, M.J., Newton, P.S. and Tipton, M.J. (2009) Ventilated Vest and Tolerance for Intermittent Exercise in Hot, Dry Conditions with Military Clothing. Aviation, Space, and Environmental Medicine, 80, 353-359.

http://dx.doi.org/10.3357/ASEM.2411.2009 
[14] Glitz, K.J., Seibel, U., Rohde, U., Gorges, W., Witzki, A., Piekarski, C. and Leyk, D. (2015) Reducing Heat Stress under Thermal Insulation in Protective Clothing: Microclimate Cooling by a "Physiological” Method. Ergonomics, 58, 1461-1469. http://dx.doi.org/10.1080/00140139.2015.1013574

[15] Zhao, M., Gao, C.S., Li, J. and Wang, F.M. (2015) Effects of Two Cooling Garments on Post-Exercise Thermal Comfort of Female Subjects in the Heat. Fibers and Polymers, 16, 1403-1409. http://dx.doi.org/10.1007/s12221-015-1403-0

[16] Burton, D. (1969) Engineering Aspects of Personal Conditioning. Proceedings of the Symposium on Individual Cooling.

[17] Edwards, R., Harrison, M. and Paine, K. (1976) Evaluation of the Liquid Conditioned Coverall during Simulated Cockpit Standby in the Heat. Royal Air Force Institute of Aviation Aircrew Equipment Group, Report.

[18] Richardson, G., Cohen, J.B., Mcphate, D.C. and Hayes, P.A. (1988) A Personal Conditioning System Based on a Liquid-Conditioned Vest and a Thermoelectric Supply System. Ergonomics, 31, 1041-1047. http://dx.doi.org/10.1080/00140138808966743

[19] Thornley, L.J., Cheung, S.S. and Sleivert, G.G. (2003) Responsiveness of Thermal Sensors to Nonuniform Thermal Environments and Exercise. Aviation, Space, and Environmental Medicine, 74, 1135-1141.

[20] Webb, P., Troutman Jr., S.J. and Annis, J.F. (1970) Automatic Cooling in Water Cooled Space Suits. Aerospace Medicine, 41, 269-277.

[21] Kim, J.-H., Coca, A., Jon Williams, W. and Roberge, R.J. (2011) Effects of Liquid Cooling Garments on Recovery and Performance Time in Individuals Performing Strenuous Work Wearing a Firefighter Ensemble. Journal of Occupational and Environmental Hygiene, 8, 409-416. http://dx.doi.org/10.1080/15459624.2011.584840

[22] Kim, J.-H., Coca, A., Jon Williams, W. and Roberge, R.J. (2011) Subjective Perceptions and Ergonomics Evaluation of a Liquid Cooled Garment Worn under Protective Ensemble during an Intermittent Treadmill Exercise. Ergonomics, 54, 626-635. http://dx.doi.org/10.1080/00140139.2011.583362

[23] Speckman, K.L., Allan, A.E., Sawka, M.N., Young, A.J., Muza, S.R. and Pandolf, K.B. (1988) Perspectives in Microclimate Cooling Involving Protective Clothing in Hot Environments. International Journal of Industrial Ergonomics, 3, 121-147. http://dx.doi.org/10.1016/0169-8141(88)90015-7

[24] Bartkowiak, G., Dąbrowska, A. and Marszałek, A. (2014) Assessment of the Human Responses to the Influence of Personal Liquid Cooling System in the Hot Environment. International Journal of Clothing Science and Technology, 26, 145-163. http://dx.doi.org/10.1108/IJCST-03-2013-0024

[25] Teunissen, L.P.J., Wang, L.-C., Chou, S.-N., Huang, C.-H., Jou, G.-T. and Daanen, H.A.M. (2014) Evaluation of Two Cooling Systems under a Firefighter Coverall. Applied Ergonomics, 45, 1433-1438. http://dx.doi.org/10.1016/j.apergo.2014.04.008

[26] Cadarette, B.S., Cheuvront, S.N., Kolka, M.A., Stephenson, L.A., Montain, S.J. and Sawka, M.N. (2006) Intermittent Microclimate Cooling during Exercise-Heat Stress in US Army Chemical Protective Clothing. Ergonomics, 49, 209219. http://dx.doi.org/10.1080/00140130500436106

[27] Vernieuw, C.R., Stephenson, L.A. and Kolka, M.A. (2007) Thermal Comfort and Sensation in Men Wearing a Cooling System Controlled by Skin Temperature. Human Factors: The Journal of the Human Factors and Ergonomics Society, 49, 1033-1044. http://dx.doi.org/10.1518/001872007X249893

[28] Porticos (2015) Porticool Personal Cooling System. http://www.porticos.net/portfolio/porticool-personal-cooling-system

[29] Zhang, Y., Bishop, P.A., Green, J.M., Richardson, M.T. and Schumacker, R.E. (2010) Evaluation of a Carbon Dioxide Personal Cooling Device for Workers in Hot Environments. Journal of Occupational and Environmental Hygiene, 7, 389-396. http://dx.doi.org/10.1080/15459621003785554

[30] Banta, G. and Braun, D. (1992) Heat Strain during At-Sea Helicopter Operations and the Effect of Passive Microclimate Cooling. Aviation, Space, and Environmental Medicine, 63, 881-885.

[31] Bennett, B.L., Hagan, R.D., Huey, K.A., Minson, C. and Cain, D. (1995) Comparison of Two Cool Vests on Heat-Strain Reduction While Wearing a Firefighting Ensemble. European Journal of Applied Physiology and Occupational Physiology, 70, 322-328. http://dx.doi.org/10.1007/BF00865029

[32] Bain, B. (1991) Effectiveness of Ice-Vest Cooling in Prolonging Work Tolerance Time during Heavy Exercise in the Heat for Personnel Wearing Canadian Forces Chemical Defence Ensembles. DTIC Document.

[33] Kaufman, J.W. and Fatkin, L.T. (2001) Assessment of Advanced Personal Cooling Systems for Use with Chemical Protective Outer Garments. DTIC Document.

[34] Kenny, G.P., Schissler, A.R., Stapleton, J., Piamonte, M., Binder, K., Lynn, A., Lan, C.Q. and Hardcastle, S.G. (2011) Ice Cooling Vest on Tolerance for Exercise under Uncompensable Heat Stress. Journal of Occupational and Environmental Hygiene, 8, 484-491. http://dx.doi.org/10.1080/15459624.2011.596043 
[35] House, J., Lunt, H.C., Taylor, R., Milligan, G., Lyons, J.A. and House, C.M. (2013) The Impact of a Phase-Change Cooling Vest on Heat Strain and the Effect of Different Cooling Pack Melting Temperatures. European Journal of Applied Physiology, 113, 1223-1231. http://dx.doi.org/10.1007/s00421-012-2534-2

[36] Yang, Y., Stapleton, J., Diagne, B.T., Kenny, G.P. and Lan, C.Q. (2012) Man-Portable Personal Cooling Garment Based on Vacuum Desiccant Cooling. Applied Thermal Engineering, 47, 18-24. http://dx.doi.org/10.1016/j.applthermaleng.2012.04.012

[37] Enescu, D. and Virjoghe, E.O. (2014) A Review on Thermoelectric Cooling Parameters and Performance. Renewable and Sustainable Energy Reviews, 38, 903-916. http://dx.doi.org/10.1016/j.rser.2014.07.045

[38] Tritt, T.M. (2002) Thermoelectric Materials: Principles, Structure, Properties, and Applications. In: Encyclopedia of Materials: Science and Technology, Elsevier, Amsterdam, 1-11.

[39] Rowe, D.M. (2005) Thermoelectrics Handbook: Macro to Nano. CRC Press, Boca Raton. http://dx.doi.org/10.1201/9781420038903

[40] Riffat, S.B. and Ma, X. (2004) Improving the Coefficient of Performance of Thermoelectric Cooling Systems: A Review. International Journal of Energy Research, 28, 753-768. http://dx.doi.org/10.1002/er.991

[41] Jeong, E.S. (2014) A New Approach to Optimize Thermoelectric Cooling Modules. Cryogenics, 59, 38-43. http://dx.doi.org/10.1016/j.cryogenics.2013.12.003

[42] Tanaka, K., Nakamura, K. and Katafuchi, T. (2014) Self-Perspiration Garment for Extravehicular Activity Improves Skin Cooling Effects without Raising Humidity. Acta Astronautica, 104, 260-265. http://dx.doi.org/10.1016/j.actaastro.2014.08.009

[43] Chan, A.P., Wong, F.K.W., Li, Y., Wong, D.P. and Guo, Y.P. (2015) Evaluation of a Cooling Vest in Four Industries in Hong Kong. Journal of Civil Engineering and Architecture Research, 2, 677-691.

[44] Lu, Y., Wei, F.R., Lai, D.D., Shi, W., Wang, F.M., Gao, C.S. and Song, G.W. (2015) A Novel Personal Cooling System (PCS) Incorporated with Phase Change Materials (PCMs) and Ventilation Fans: An Investigation on Its Cooling Efficiency. Journal of Thermal Biology, 52, 137-146. http://dx.doi.org/10.1016/j.jtherbio.2015.07.002

[45] Gouvernement du Québec (2001) Regulation Respecting Occupational Health and Safety. Éditeur officiel du Québec.

[46] Kenny, G.P., Vierula, M., Maté, J., Beaulieu, F., Hardcastle, S.G. and Reardon, F. (2012) A Field Evaluation of the Physiological Demands of Miners in Canada’s Deep Mechanized Mines. Journal of Occupational and Environmental Hygiene, 9, 491-501. http://dx.doi.org/10.1080/15459624.2012.693880

[47] Barwood, M., Davey, S., House, J.R. and Tipton, M.J. (2009) Post-Exercise Cooling Techniques in Hot, Humid Conditions. European Journal of Applied Physiology, 107, 385-396. http://dx.doi.org/10.1007/s00421-009-1135-1

[48] Cadarette, B.C., et al. (1991) A Physiological Evaluation of a Prototype Air-Vest Microclimate Cooling System. DTIC Document.

[49] Chan, A.P.C., Yang, Y., Wong, D.P., Lam, E.W.M. and Li, Y. (2013) Factors Affecting Horticultural and Cleaning Workers' Preference on Cooling Vests. Building and Environment, 66, 181-189. http://dx.doi.org/10.1016/j.buildenv.2013.04.021 